\title{
TRIPLE PHASE CT EVALUATION OF SUPERNUMERARY KIDNEY: A CASE REPORT
}

\author{
V. Sarath Chand ${ }^{1}$, P. Venkateswara Rao², B. Anuradha ${ }^{3}$
}

\section{HOWTOCITETHISARTICLE:}

V. Sarath Chand, P. Venkateswara Rao, B. Anuradha. "Triple Phase CT Evaluation of Supernumerary Kidney: A Case Report". Journal of Evolution of Medical and Dental Sciences 2014; Vol. 3, Issue 70, December 15; Page: 15017-15021, DOI:10.14260/jemds/2014/4020

ABSTRACT: Fused supernumerary kidney with bifid ureters was diagnosed in a 40 year old female patient using ultrasonography and triple phased computed tomography (CT).The CTrevealed two seperate renal arteries supplying each of the left kidney, and two separate renal veins draining into the inferior vena cava. Supernumerary kidney is a rare congenital anomaly, fewer than 100 cases have been reported after years. A fused supernumerary kidney is still rarer in practice.

KEYWORDS: Supernumerary Kidney.Bifid.Duplex.

CASE REPORT:A 40 year old female patient presented with burning micturition since 2 months. General evaluation did not reveal much information, routine hematological and biochemical investigations were within normal limits, except for a raised leukocyte count.

Ultrasonography of the abdomen revealed two kidneys on the left side which are joined by a thin parenchymal bridge with the pelvicalyceal system of one kidney directed medially measuring $(7 \times 3.7 \mathrm{~cm})$ and the other kidney directed anterolaterally measuring $(6.1 \times 3.1 \mathrm{~cm})$ (Fig.1). Calculus noted, measuring $1 \mathrm{~cm}$ noted in the upper calyx of the right kidney with no hydronephrosis, calculi measuring up to $1 \mathrm{~cm}$ noted in lower kidney on the left side with no significant hydronephrosis. Bladder showed multiple internal echoes with no increase in wall thickness.

Fig. 1: Sonographic image showing supernumerary kidney attached to lower pole of left kidney by a parenchymal bridge and showing two collecting systems.

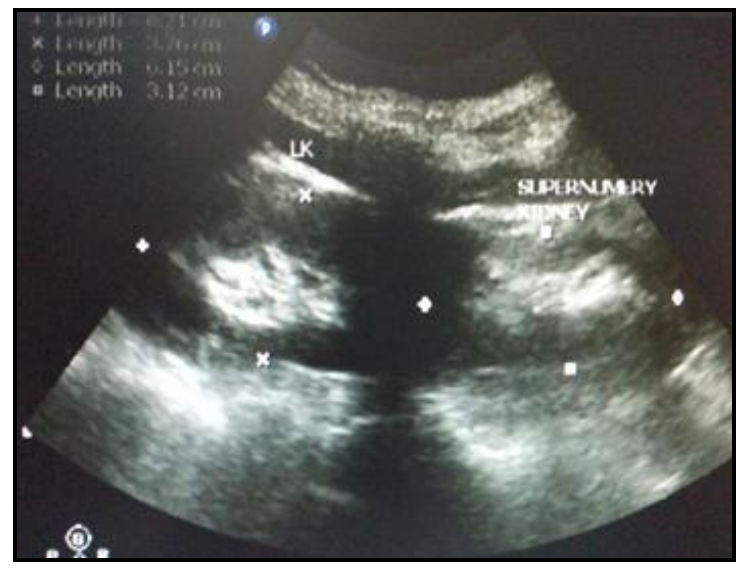

\section{Fig. 1}

A triple phase CT scan with intravenous contrast administration revealed a normal right kidney measuring $(9.7 \times 4.3 \mathrm{~cm})$ with a calculus measuring $(1.3 \times 0.7 \mathrm{~cm})$ and two left kidneys. The cranially located kidney on left side measured $(9.6 \times 4.2 \mathrm{~cm})$ and caudally located kidney measured 


\section{CASE REPORT}

$(8.6 \times 3.5 \mathrm{~cm})$ and calculi of varying sizes are seen in caudally located kidney largest measuring $(1.4 \times 1.2 \mathrm{~cm})$. The kidneys are partially fused and demonstrated a small parenchymal bridge between them. (Fig.2).

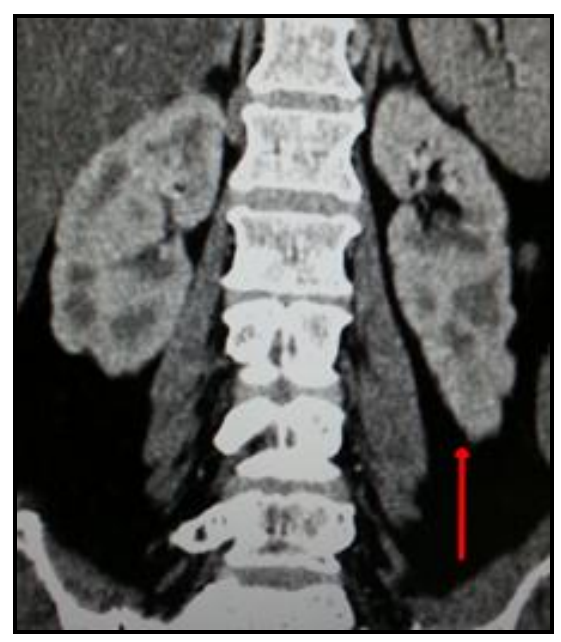

\section{Fig. 2}

Fig. 2: Coronal reconstruction of contrast enhanced CT image in arterial phase shows two normally located kidneys on either side and supernumerary kidney fused to the lower pole of the left kidney (Depicted by arrow).

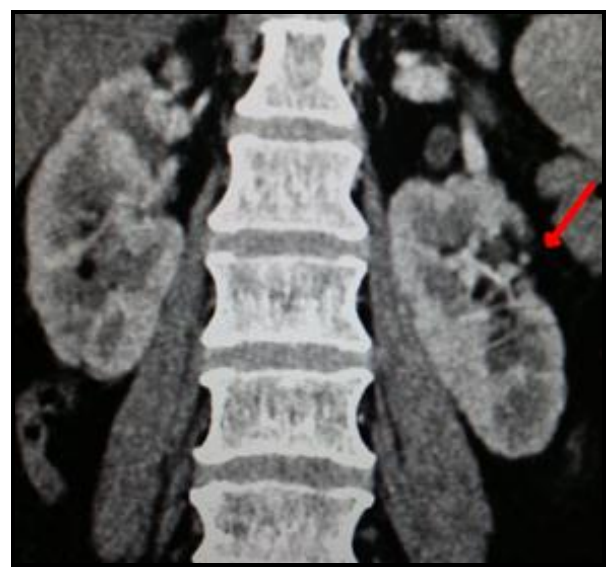

Fig. 3a

Fig. 3(a): Coronal reconstruction of contrast enhanced CT image in arterial phase showing anterolateral rotation of pelvis in supernumerary kidney.

Two distinct main renal arteries supplied the fused left kidneys. The cranially placed kidney received its arterial supply from left renal artery and drained by left renal vein. The caudally placed kidney received its arterial supply from another artery arising from abdominal aorta just before its bifurcation on left side, and drained by a vein which drains into inferior vena cava which is coursing posteriorly to the abdominal aorta. The vascular supply to right kidney was through a single main artery and renal vein and didn't show any anatomical variation. (Fig.3.a, 3.b) (Fig.4, 5). 


\section{CASE REPORT}

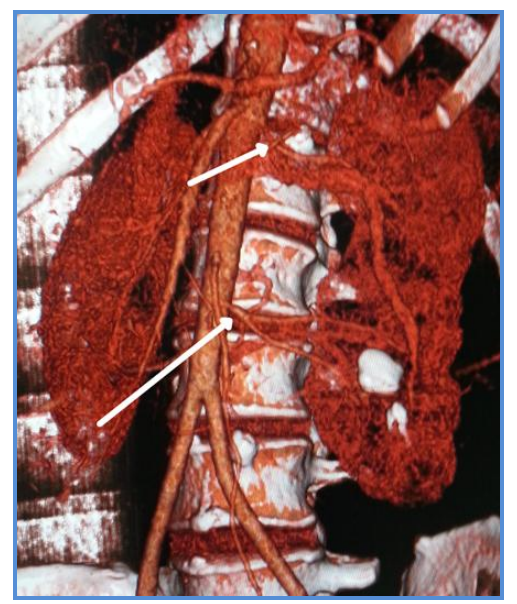

Fig. 3b

Fig. 3(b): Triphasic CT with IV contrast administration. 3D volume rendering of arterial phase (Oblique view) showing normalright kidney, left kidney and supernumerary on left side fused to lower pole of left kidney with calculi with in it. Short arrow indicates normal left renal artery supplying normal left kidney and long arrow indicates accessory renal artery arising from the abdominal aorta supplying supernumerary kidney on left side.

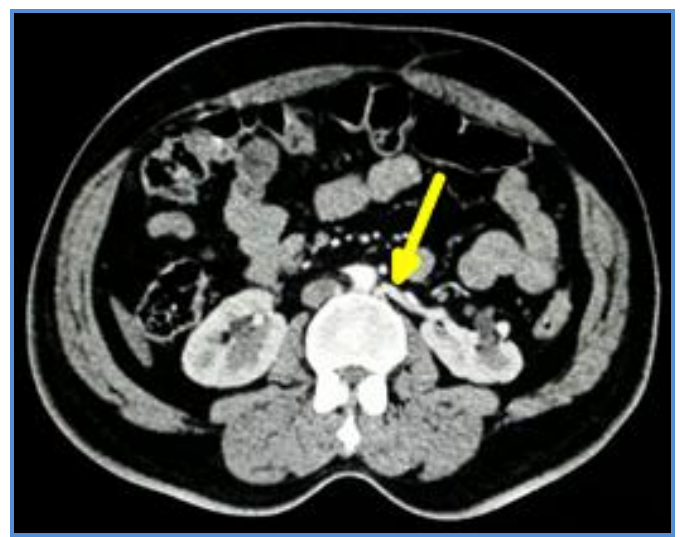

Fig. 4

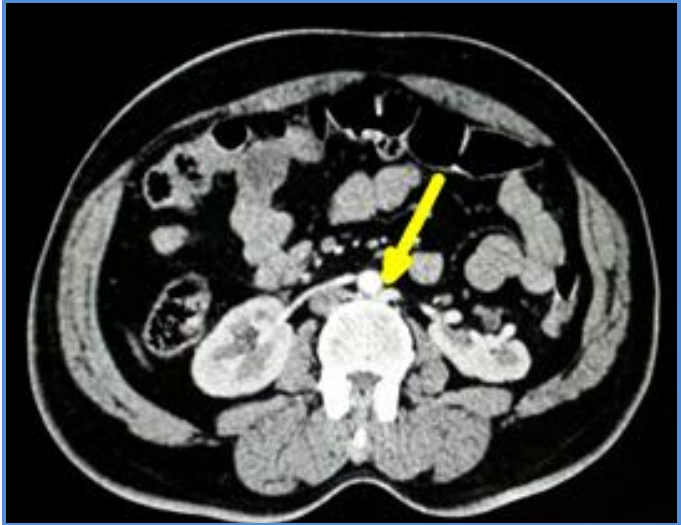

Fig. 5

Fig. 4, 5: Axial contrast CT images showing a vein draining the supernumerary kidney on left side passing posteriorly to the abdominal aorta and opening into the inferior vena cava.

A normal excretory phase was demonstrated by the kidneys bilaterally with no delay in excretion of contrast. Supernumerary kidneys on the left showed a bifid ureter. The ureter from the cranially placed kidney passed anteriorly and joined the pelvis of caudally positioned kidney at the pelviureteric junction to form a single ureter (Fig.6).

Pelvicalyceal systems of both kidneys were not dilated. Pelvicalyceal system of kidney lying cranially was normally sited. The caudally placed kidney was malrotated with its pelvicalyceal system facing anterolaterally.The right pelvicalyceal system and right ureter didn't reveal any anatomical variation or pathology. Ureterovescial junctions were normal and there was no ectopic ureteric opening bilaterally. 


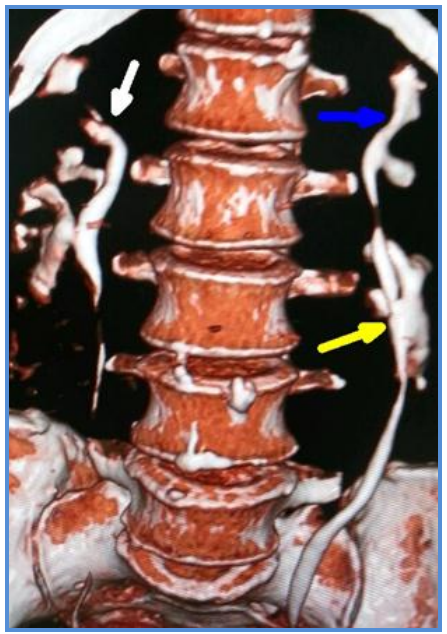

Fig. 6

Fig. 6: 3D volume rendering of excretory phase (oblique view) of bilateral pelvicalyceal systems and ureters show a normal right pelvicalyceal system(white arrow) and ureter, and left ureter from cranially placed kidney(Blue arrow) passes anteriorly and joins the pelvis of caudally placed kidney at pelvi ureteric junction(Yellow arrow) to form a single ureter.

CT didn't reveal features relevant to cystitis and the patient was medically managed for burning micturition.

DISCUSSION: Supernumerary kidney is a third kidney (In addition to the two independent kidneys). This is a rare congenital anomaly of urinary tract.(2) There are several theories to explain the occurrence of supernumerary kidney: a) bifurcation of ureteric bud with independent penetration into metanephrogenic blastema that develop and divide in two kidneys; b) two independent ureteral buds that penetrate the metanephrogenic blastema that divides into two and c) fragmentation of metanephrogenic blastema due to linear infarcts.(1)(3)

Supernumerary kidney needs to be differentiated from the more commonly occurring duplex kidney, which is defined as having two pelvicalyceal systems that are associated with a single ureter or with double ureters. Supernumerary kidney in contrast, is thought to be an accessory organ with a separate arterial supply, venous drainage, collecting system, and distinct encapsulated tissue. It may be either totally separate from normal kidney or connected to it by loose areolar tissue, acting as a bridge between two kidneys. ${ }^{(2)}$

\begin{tabular}{|l|l|l|}
\hline \multicolumn{1}{|c|}{ Structure } & \multicolumn{1}{|c|}{ Supernumerary kidney } & \multicolumn{1}{c|}{ Duplex kidney } \\
\hline Parenchyma & $\begin{array}{l}\text { Usually completely separate, but } \\
\text { there may be partial fusion }\end{array}$ & $\begin{array}{l}\text { Both poles firmly attached to } \\
\text { each other. }\end{array}$ \\
\hline Capsule & Usually separate & Single continuous capsule \\
\hline Number of calyces & Greater & $\begin{array}{l}\text { Doesn't exceed from the } \\
\text { opposite kidney }\end{array}$ \\
\hline Vascular supply & $\begin{array}{l}\text { Separate arterial supply and } \\
\text { venous drainage }\end{array}$ & Same vascular supply \\
\hline \multicolumn{2}{|c|}{ Differences between supernumery kidney and duplex kidney. ${ }^{(4)}$} \\
\hline
\end{tabular}


Site of supernumerary kidney may vary, but is usually smaller commonly seen on left side of abdomen(2) and caudal in position to the ipsilateral normal kidney. When present caudally a bifid ureter is the most commonly seen presentation. If the supernumerary kidney is located cranially in relation to the normal kidney, ureter is usually completely separate and may enter bladder ectopically, in which case the Weigert-Meyer rule may be followed and ureter may insert medially and inferiorly into bladder.(2) Sometimes ureter of supernumery kidney may be associated with ectopic opening such as into the vagina.

Most commonly associated pathologies with supernumery kidney include hydronephrosis, pyelonephritis, pyonephrosis, renal and ureteral calculi, carcinoma, papillary cystadenoma and Wilm's tumor.

Management of this condition depends on symptoms and function of supernumery kidney. If the patient becomes symptomatic due to the presence of calculi, it needs medical or surgical intervention. If the kidney is diseased or nonfunctional, nephrectomy is usually the preferred procedure.

\section{REFERENCES:}

1. Luciano A, Favorito, Ana Raquel M. Morais; Evaluation of supernumerary kidney with fusion using magnetic resonance imaging: IBJU: 2012; 38(3): 428-429.

2. Jaishilpa Suresh, Navin Gnanasekharan, Bhawna Dev. Fused supernumerary kidney. radiology case reports 2011;6(4):1-4.

3. Koureas AP, Panourgias EC, Gouliamos AD, Trakadas SJ; Vlahos LJ; Imaging of supernumerary kidney. Eur Radiol.2000; 10:1722-3.

4. Binit Sureka, Mahesh Kumar Mittal, Aliza Mittal, Mukul Sinha, Brijj Bhushan Thukral; supernumerary kidneys-a rare anatomical variant: Springer - Verlag France 2013; 14 May 2013.

\section{AUTHORS:}

1. V. Sarath Chand

2. P. Venkateswara Rao

3. B. Anuradha

\section{PARTICULARS OF CONTRIBUTORS:}

1. Assistant Professor, Department of Radiology, Rangaraya Medical College, Kakinada.

2. Senior Resident, Department of Radiology, Rangaraya Medical College, Kakinada.

3. Associate Professor and HOD, Department of Radiology, Rangaraya Medical College, Kakinada.

\section{NAME ADDRESS EMAIL ID OF THE} CORRESPONDING AUTHOR:

Dr. V. Sarath Chand, Flat No. F (C), 2-19-11, Vamsi Krishna Residency, Opposite, RMC Mens Hostel, Madhav Nagar, Kakinada-533003, East Godavari District, A. P. Email: drsarath279@gmail.com

Date of Submission: 20/11/2014. Date of Peer Review: 21/11/2014. Date of Acceptance: 10/12/2014. Date of Publishing: 15/12/2014. 